\section{Preparation of Dry Nitrocellulose Membranes and Nitrocellulose Particles}

'Gradocol' membranes of pore diameter less than $400 \mathrm{~m} \mu$ change their characteristics when normally allowed to dry in air. These changes, which are irreversible, include a decrease in thickness and pore diameter when the membranes are re-equilibrated in water (Table 1). Membranes dried in this way and stored in the dark in contact with one another in a weighing bottle 2 in. diam. $\times 3$ in. height tend to coalesce and decompose after long periods of storage. Membranes of low porosity are not easily re-wetted with water after being dry for several days. 'Gradocol' membranes may be dried by the method outlined below and stored for long periods without impairment of their characteristics.
Collodion particles used for adsorption studies were obtained, either by the Loeb method $^{3}$ or by grinding under water in a ball-mill thin strips of those normally discarded portions of 'Gradocol' membranes prepared by the Elford technique ${ }^{4}$. The nitrocellulose particles prepared by the latter method were graded, when dry, by passage through a No. 100 B.S.S. sieve. They were then shaken with water in a stoppered cylinder and separated from finer particles by decantation. This process was repeated until the supernatant was clear. The collodion particles were activated by the method described by Sollner, Abrams and Carr 5 .

Membranes or nitrocellulose particles treated by the method described above may be stored or transported in the dry state. The membranes may be marked with Indian ink and stored in the dark

Table 1

\begin{tabular}{|c|c|c|c|c|c|c|c|c|c|}
\hline \multicolumn{5}{|c|}{ Before treatment } & \multicolumn{5}{|c|}{ After treatment } \\
\hline $\begin{array}{c}\text { Thickness } \\
\text { (mm.) }\end{array}$ & $R F W$ & $S W C$ & $\begin{array}{l}A P D \\
(\mathrm{~m} \mu)\end{array}$ & $\begin{array}{l}\text { Bursting pressure } \\
\text { (lb./sg. in. } 8 \mathrm{~mm} .)\end{array}$ & $\underset{(\mathrm{mm} .)}{\text { Thickness }}$ & $R F W$ & SWC & $\underset{(\mathrm{m} \mu)}{A P D}$ & $\begin{array}{l}\text { Bursting pressure } \\
\text { (lb./sq. in. } 8 \mathrm{~mm} \text {.) }\end{array}$ \\
\hline $\begin{array}{l}0 \cdot 147 \\
0 \cdot 190\end{array}$ & $\begin{array}{l}0 \cdot 353 \\
1 \cdot 63\end{array}$ & $\begin{array}{l}0.863 \\
0.857\end{array}$ & $\begin{array}{l}150 \\
323\end{array}$ & $\begin{array}{l}16 \\
13\end{array}$ & $\begin{array}{l}0.133 \\
0.180\end{array}$ & $\begin{array}{l}0.208 \\
0.829\end{array}$ & $\begin{array}{l}0.800 \\
0.821\end{array}$ & $\begin{array}{l}119 \\
235\end{array}$ & $\begin{array}{l}19 \\
17\end{array}$ \\
\hline
\end{tabular}

Table 2

\begin{tabular}{|c|c|c|c|c|c|c|c|c|c|}
\hline \multicolumn{5}{|c|}{ Before treatment } & \multicolumn{5}{|c|}{ After treatment } \\
\hline $\begin{array}{l}\text { Thickness } \\
\text { (mm.) }\end{array}$ & $R F W$ & $S W C$ & $\begin{array}{l}A P D \\
(\mathrm{~m} \mu)\end{array}$ & $\begin{array}{l}\text { Bursting pressure } \\
\text { (lb./sq. in. } 8 \mathrm{~mm} \text {.) }\end{array}$ & $\begin{array}{l}\text { Thickness } \\
\text { (mm.) }\end{array}$ & $R F W$ & $S W C$ & $\underset{(\mathrm{m} \mu)}{A P D}$ & $\begin{array}{l}\text { Bursting pressure } \\
\text { (lb./sq. in. } 8 \mathrm{~mm} \text {.) }\end{array}$ \\
\hline $\begin{array}{l}0 \cdot 038 \\
0 \cdot 054 \\
0 \cdot 109 \\
0 \cdot 168 \\
0 \cdot 232 \\
0 \cdot 143 \\
0 \cdot 154 \\
0 \cdot 138 \\
0 \cdot 149 \\
0 \cdot 119 \\
0 \cdot 139\end{array}$ & $\begin{array}{c}0 \cdot 0000347 \\
0 \cdot 0000797 \\
0 \cdot 0148 \\
0 \cdot 0891 \\
0 \cdot 391 \\
1 \cdot 77 \\
3 \cdot 84 \\
10 \cdot 0 \\
23 \cdot 9 \\
42 \cdot 9 \\
59 \cdot 9\end{array}$ & $\begin{array}{l}0 \cdot 296 \\
0 \cdot 470 \\
0.819 \\
0.869 \\
0.874 \\
0.808 \\
0.828 \\
0.822 \\
0.830 \\
0 \cdot 791 \\
0 \cdot 812\end{array}$ & $\begin{array}{r}2 \cdot 5 \\
9 \cdot 6 \\
31 \\
75 \\
156 \\
346 \\
504 \\
815 \\
1,253 \\
1,723 \\
2,008\end{array}$ & $\begin{array}{c}100 \\
69 \\
44 \\
34 \\
17 \cdot 5 \\
13 \cdot 5 \\
23^{*} \\
16^{*} \\
11^{*} \\
12^{*} \\
\end{array}$ & $\begin{array}{l}0 \cdot 038 \\
0 \cdot 053 \\
0 \cdot 110 \\
0 \cdot 167 \\
0 \cdot 236 \\
0 \cdot 143 \\
0 \cdot 158 \\
0 \cdot 137 \\
0 \cdot 151 \\
0 \cdot 121 \\
0 \cdot 140\end{array}$ & $\begin{array}{c}0 \cdot 0000416 \\
0 \cdot 000718 \\
0 \cdot 0147 \\
0 \cdot 0905 \\
0 \cdot 401 \\
1 \cdot 81 \\
3 \cdot 80 \\
9 \cdot 97 \\
23 \cdot 0 \\
41 \cdot 7 \\
58 \cdot 9\end{array}$ & $\begin{array}{l}0.300 \\
0 \cdot 460 \\
0 \cdot 803 \\
0 \cdot 859 \\
0 \cdot 865 \\
0 \cdot 820 \\
0 \cdot 818 \\
0 \cdot 824 \\
0 \cdot 810 \\
0 \cdot 782 \\
0 \cdot 811\end{array}$ & $\begin{array}{c}2 \cdot 8 \\
9 \cdot 2 \\
31 \\
76 \\
159 \\
347 \\
504 \\
813 \\
1,250 \\
1,700 \\
1,991\end{array}$ & $\begin{array}{c}99 \\
72 \\
42 \\
33 \\
18 \\
14 \\
23^{*} \\
16^{*} \\
11 \cdot 5^{*} \\
12^{*} \\
-\end{array}$ \\
\hline
\end{tabular}

- Values for the test when disk with hole $\mathrm{mm}$ diam was used The data shown in columns 5 and 10 indicate the relative strengths of the neribranes. The membrane was supported on a brass disk of thickness $2 \mathrm{~mm}$. having a central circular hole of diameter $4 \mathrm{~mm}$. or $8 \mathrm{~mm}$. The disk with membrane surmounted by a rubber washer was placed in a special adaptor which was clamped to the top half of an Elford ultrafliter (ref. 6) by means of a hexagonal nut. Pressure was applied to the system and increased slowly until the membrane was ruptured. The minimum pressure required to break the membrane is recorded in column 5 or 10 . The rate of flow of water $(R F W)$, specific water content $(S W C)$ and average pore diameter $(A P D)$ were determined by the methods described by Elford and Ferry (ref. 7 )

Brown ${ }^{1}$ has graded collodion membranes, after coagulation in water, by immersing them in mixtures of ethyl alcohol and water in varying proportions. Unsuccessful attempts were made in this laboratory to swell dried 'Gradocol' membranes by similar methods using various alcohols.

'Gradocol' membranes of porosities ranging from $3 \mathrm{~m} \mu$ to $2,000 \mathrm{~m} \mu$ were dried by treatment with either ethyl, $n$-propyl, isopropyl, $n$-butyl, isobutyl or amyl alcohol, followed by either chloroform, carbon tetra. chloride, dichlorethylene, benzene or petroleum ether. For the whole range of porosities, only isobutyl or amyl alcohol could be used successfully in combination with petroleum ether (preferably of boiling point $40-60^{\circ} \mathrm{C}$.) for drying the membranes without impairment to their characteristics (Table 2) (cf. Grabar ${ }^{2}$ ).

The membrane to be dried $(4.0 \mathrm{~cm}$. or $5.6 \mathrm{~cm}$. in diameter, weighing $0 \cdot 05-0 \cdot 1 \mathrm{gm}$.) was placed between folds of filter paper to remove superficial water, and then immersed in $50 \mathrm{ml}$. isobutyl or amyl alcohol. It was transferred twice to approximately $50 \mathrm{ml}$. fresh alcohol in separate closed vessels for 5-10 $\mathrm{min}$. intervals. Then the superficial alcohol was removed with filter paper and the membrane washed three times with petroleum ether in a similar manner. The membrane was dried at room temperature or $60^{\circ} \mathrm{C}$. for many months in paper envelopes or glass vessels together with others of different porosity. When reequilibrated against water, their characteristics remain unchanged from the original ; that is, thickness, rate of flow of water, mechanical strength, specific water content and porosity remain unaltered (see Table 2).

Such dried membranes of predetermined characteristics may be sealed, by means of a 5 per cent solution of nitrocellulose shreds in ether : alcohol (1:1) mixture, to the end of a narrow tube to make a filter stick or a wide tube (for example, a Gooch crucible adaptor) for use in dialysis.

\section{S. J ACOBS}

Wright-Fleming Institute of Microbiology,

$$
\begin{aligned}
& \text { St. Mary's Hospital, } \\
& \text { London, W.2. } \\
& \text { Sept. } 23 .
\end{aligned}
$$

${ }^{1}$ Brown, N., Biochem. J., 9, 591 (1915). ${ }^{2}$ Grabar. P., Cold Spring Harb. Symp. Quant. Biol., 6, 252 (1938);

${ }^{3}$ Loeb, J., J. Gen. Physiol., 5, 109 (1922-23).

4 Elford, W. J., J. Path. Bact., 34, 505 (1931).

${ }^{5}$ Sollner, K., Abrams, I., and Carr, C. W., J. Gen. Physiol., 25, 7 (1941-42).

- Elford, W. J., and Barnard, J. E., Proc. Roy. Soc., B, 109, 360 (1931).

${ }^{7}$ Elford, W. J., and Ferry, J. D., Brit. J. Exp. Path., 16, 1 (1935). 